\title{
Application of the Molecular Invariom Model for the Study of Interactions Involving Fluorine Atoms in the $\left\{\mathrm{Yb}_{2}^{\mathrm{II}}\left(\mu_{2}-\mathrm{OCH}\left(\mathrm{CF}_{3}\right)_{2}\right)_{3}\left(\mu_{3}-\right.\right.$ $\left.\left.\mathrm{OCH}\left(\mathrm{CF}_{3}\right)_{2}\right)_{2} \mathrm{Yb}^{\mathrm{III}}\left(\mathrm{OCH}\left(\mathrm{CF}_{3}\right)_{2}\right)_{2}(\mathrm{THF})\left(\mathrm{Et}_{2} \mathrm{O}\right)\right\}$ Complex
}

\author{
R. V. Rumyantsev ${ }^{a}$, G. K. Fukin ${ }^{a}$ * , E. V. Baranov ${ }^{a}$, A. V. Cherkasov ${ }^{a}$, and E. A. Kozlova ${ }^{a}$ \\ ${ }^{a}$ Razuvaev Institute of Organometallic Chemistry, Russian Academy of Sciences, Nizhny Novgorod, Russia \\ *e-mail: gera@iomc.ras.ru \\ Received April 26, 2020; revised June 19, 2020; accepted June 25, 2020
}

\begin{abstract}
The electron density distributions obtained by the quantum-chemical (density functional theory) calculations and molecular invariom model in the trimeric ytterbium complex with the hexafluoroisopropoxide ligands $\left\{\mathrm{Yb}_{2}^{\mathrm{II}}\left(\mu_{2}-\mathrm{OR}\right)_{3}\left(\mu_{3}-\mathrm{OR}\right)_{2} \mathrm{Yb}^{\mathrm{III}}(\mathrm{OR})_{2}(\mathrm{THF})\left(\mathrm{Et}_{2} \mathrm{O}\right)\right\}$ (I) (where $\mathrm{R}$ is $\mathrm{CH}\left(\mathrm{CF}_{3}\right)_{2}$, and THF is tetrahydrofuran) are compared. The main topological characteristics of the electron density at the critical points $(3,-1)$ corresponding to the interactions of the ytterbium atoms in the coordination sphere obtained using two studied approaches demonstrate excellent agreement. The maximum divergence between the density functional calculations and molecular invariom model is observed for the intramolecular interactions involving the fluorine atoms $(\mathrm{F} \cdots \mathrm{F}, \mathrm{F} \cdots \mathrm{H}$, and $\mathrm{F} \cdots \mathrm{O})$ in the structure of complex I. Geometry optimization leads to a higher number of these interactions in the complex. The energy corresponding to these interactions also increases. However, the main topological characteristics for the F $\cdots X$ interactions $(X=F, H, O)$, which can be localized in the framework of both methods, remain within the transferability index range. An analysis of the deformation electron density shows that the $\mathrm{F}^{\delta-\ldots} \mathrm{F}^{\delta-}$ interactions are determined by the correspondence of the region of electron density concentration on one of the fluorine atoms to the region of electron density depletion on the second fluorine atom regardless of the method of measuring the electron density distribution.
\end{abstract}

Keywords: F*F interactions, halogen bond, QTAIM theory, molecular invariom

DOI: $10.1134 / \mathrm{S} 1070328421020056$

\section{INTRODUCTION}

The study of the electron density (ED) distribution is an important tool for the solution of theoretical and practical problems of the modern chemical science [1-3]. The high-resolution X-ray diffraction (XRD) studies make it possible to obtain the experimental ED distribution, calculate the electrostatic potential and energy of intra- and interatomic interactions in the crystal, reveal structure-forming factors determining the structure, and establish the fragments that weakly change in related compounds [4]. This study is especially important for the correlation of the properties of compounds to the structure. However, a number of requirements is imposed on the sample in order to carry out high-resolution XRD experiments, and it is rather labor consuming to obtain a suitable single crystal. This fact substantially restricts the experimental study of the ED in practically significant compounds. A compromise solution is to obtain the ED distribution in compounds from theoretical calculations by the density functional (DFT) method [5-7].
The procedure based on the invariom (invariant atom) was developed for the study of the ED distribution in organic and organoelement compounds with relatively light atoms (Periods 1-3) [8, 9]. This experimental-theoretical approach makes it possible to obtain the ED distribution on the basis of data of routine XRD studies and theoretical calculations. The improved method based on the determination of the molecular invariom was applied for the organometallic compounds [10-12]. The use of this method provides an information about the topology of the ED in molecules with good accuracy [13, 14]. However, the majority of studies in this area is devoted to the transferability of the topological characteristics in the coordination sphere of the metal atom [15-17].

Intramolecular weak nonvalent interactions are significant among structural features of many biologically active compounds for the determination of the molecular conformation and physicochemical properties manifested by the molecule [18]. Intramolecular nonvalent interactions in organometallic complexes 


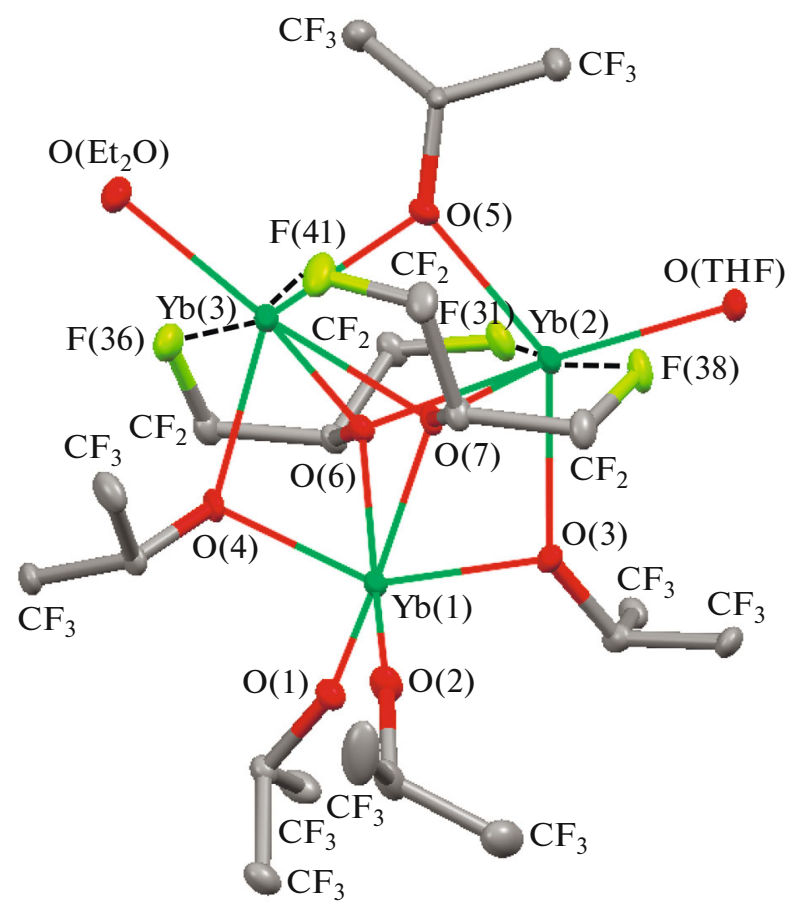

Fig. 1. Molecular structure of complex I. Thermal ellipsoids are given with $30 \%$ probability. Hydrogen atoms are omitted for clarity.

are also important. For example, the $\mathrm{C}-\mathrm{F} \rightarrow \mathrm{Ln}$ interactions are possible in the lanthanide complexes with the fluorinated ligands, due to which, in particular, these complexes are catalytically active $[19,20]$. It is also significant that these interactions determine the thermal stability of the complexes [21, 22].

Some lanthanide complexes with hexafluoroisopropoxide ligands manifest the promising luminescence properties $[23,24]$. Our recent study of the ED topology in the trimeric europium complex demonstrated numerous intramolecular interactions involving the fluorine atoms $\mathrm{F} \cdots \mathrm{X}(\mathrm{X}=\mathrm{Eu}, \mathrm{F}, \mathrm{H}, \mathrm{O})$ [25].

This work is devoted to the study of the principal possibility to obtain an information about the topological characteristics of the ED at the critical points (CP) corresponding to the interactions involving the fluorine atoms in the $\left\{\mathrm{Yb}_{2}^{\mathrm{II}}\left(\mu_{2}-\mathrm{OCH}\left(\mathrm{CF}_{3}\right)_{2}\right)_{3}\left(\mu_{3^{-}}\right.\right.$ $\left.\left.\mathrm{OCH}\left(\mathrm{CF}_{3}\right)_{2}\right)_{2} \mathrm{Yb}^{\mathrm{III}}\left(\mathrm{OCH}\left(\mathrm{CF}_{3}\right)_{2}\right)_{2}(\mathrm{THF})\left(\mathrm{Et}_{2} \mathrm{O}\right)\right\}$ complex (I) using the molecular invariom model.

\section{EXPERIMENTAL}

The full optimization of the geometry of complex I was performed by the DFT method implemented in the Gaussian 09 [26] program package using the B3LYP hybrid functional. The $6-31+\mathrm{G}^{*}$ basis set was used for the organic moiety [27-31], and the ECP28MWB pseudopotential was used for the lanthanide atoms [32]. The electron density function for the
ECP (effective core potential) was calculated using the Molden2aim program.

The topological analysis of the theoretical function of the ED distribution obtained by the DFT calculation was performed using the AIMALL program [33].

The routine set of experimental XRD data was used for the experimental-theoretical refinement. The one-point calculation of an isolated molecule of complex I was performed by the DFT method (B3LYP/DZP) [34] using the Gaussian 09 program [26]. Then the complex molecule was placed in the pseudocubic cell $(a=30 \AA)$. The structural amplitudes $\left(\sin \theta / \lambda=1.155 \AA^{-1}\right)$ were calculated using the Tonto program [35]. The populations of the spherically symmetric valent shell $\left(P_{\mathrm{val}}\right)$ and the multipole parameters $\left(P_{\mathrm{lm}}\right)$ describing its deformation together with the corresponding expansion-compression coefficients $\left(k, k^{\prime}\right)$ for each atom in complex I were obtained from the structural amplitudes for the cubic cell using the MoPro program [36]. The calculated values of $P_{\text {val }}, P_{\mathrm{lm}}, k$, and $k^{\prime}$ were used (but they themselves were not refined) for the refinement of the atomic coordinates and their thermal parameters by the experimental reflections of the routine data in the real symmetry of complex I. The topological analysis of the experimental-theoretical function of the ED distribution was performed using the WinXPRO program [37].

An analysis of the deformation electron density (DED) distribution in the region of nonvalent interactions between the fluorine atoms in complex I was performed using the MoPro [36] and Multiwfn v. 3.3.8 [38] programs.

\section{RESULTS AND DISCUSSION}

The crystal structure of complex I was determined by XRD and described in detail previously [23]. The molecular structure of the complex is presented in Fig. 1. An analysis of the geometric characteristics assumes (by analogy to the related europium complex [25]) that the structure contains many intramolecular nonvalent interactions involving the fluorine atoms.

To check this hypothesis, we performed the quantum-chemical (DFT) study of complex I by the DFT method (B3LYP/6-31+G*, ECP28MWB) with geometry optimization. Then the model of complex I obtained by the DFT calculation will be named $\mathbf{I}_{\text {isol }}$ for convenience. The molecular invariom of complex I was simultaneously calculated using the known methodology, and the refinement was performed by the routine experimental data $\left(\mathbf{I}_{\text {inv }}\right)$. Thus, the experimental-theoretical ED distribution in complex $\mathbf{I}_{\text {inv }}$ was obtained. The molecular graphs for the $\mathbf{I}_{\text {isol }}$ and $\mathbf{I}_{\text {inv }}$ models demonstrating all interactions in the coordination sphere of the ytterbium atoms are presented in Fig. 2. 
(a)

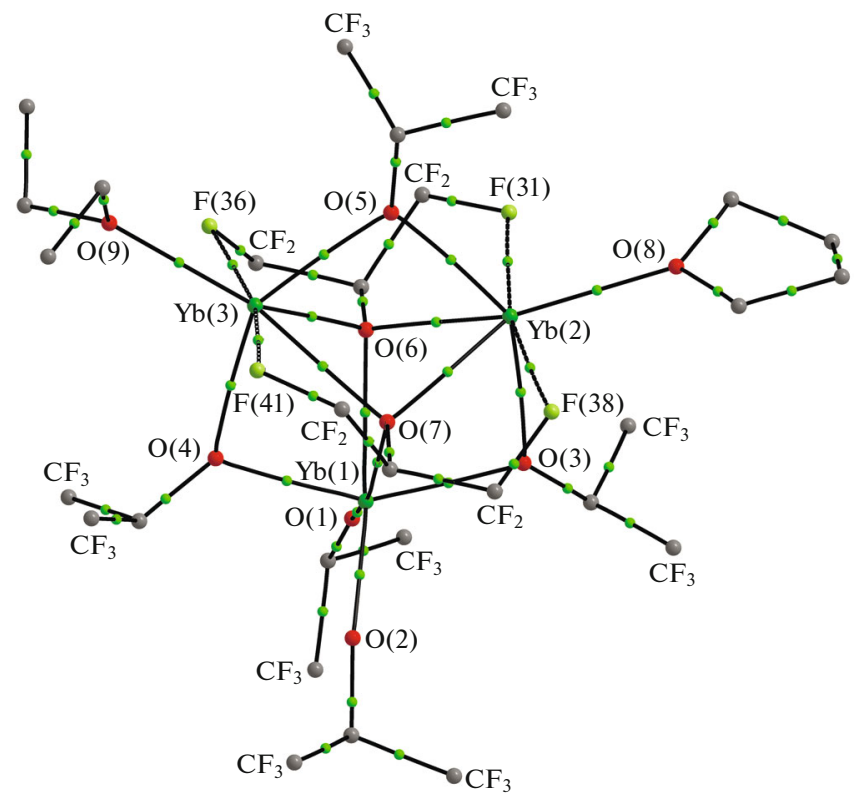

(b)

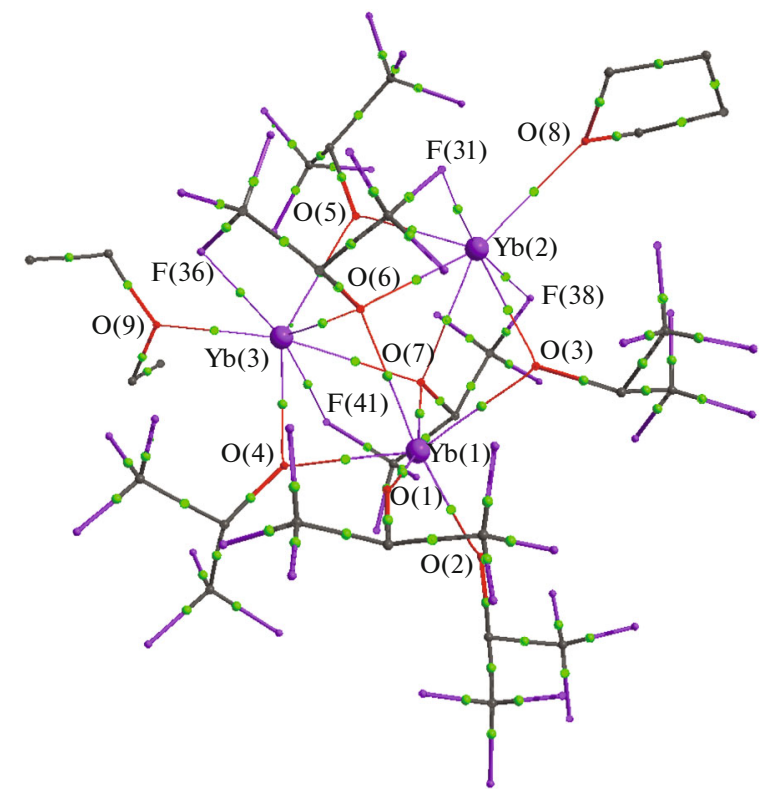

Fig. 2. (a) Theoretical ( $\left.\mathbf{I}_{\text {isol }}\right)$ and (b) experimental-theoretical ( $\left.\mathbf{I}_{\text {inv }}\right)$ molecular graphs of complex $\mathbf{I}$. Only selected CP (3, -1) corresponding to the valent interactions and nonvalent contacts $\mathrm{C}-\mathrm{F} \rightarrow \mathrm{Ln}$ in the coordination sphere of the ytterbium atoms are presented for clarity. Hydrogen atoms are omitted.

It should be mentioned that the molecular invariom model more precisely reproduces the main geometric characteristics of complex I obtained by the routine XRD method than those calculated by the theoretical quantum-chemical DFT study (Table 1). The average deviation of the $\mathrm{Yb}-\mathrm{O}$ and $\mathrm{Yb} \cdots \mathrm{F}$ bonds for $\mathbf{I}_{\text {inv }}$ is $0.003 \AA$, whereas for $\mathbf{I}_{\text {isol }}$ this value is $0.024 \AA$. The highest changes do not exceed 0.009 and $0.094 \AA$, respectively. Interestingly, in the cases of both $\mathbf{I}_{\text {isol }}$ and $\mathbf{I}_{\text {inv }}$, the highest deviations from the XRD data are observed for the coordination bonds with the neutral solvents $\mathrm{Yb}(2)-\mathrm{O}(8)_{\mathrm{THF}}$ and $\mathrm{Yb}(3)-\mathrm{O}(9)_{\mathrm{EtOEt}}$.
The atomic charges on the organic fragment of complex I obtained from the theoretical $\left(\mathbf{I}_{\text {isol }}\right)$ and experimental-theoretical ( $\left.\mathbf{I}_{\text {inv }}\right)$ ED distributions are well consistent (Table 2). All fluorine and oxygen atoms are characterized by a negative charge. The highest difference in the charges is observed on the atoms of the neutral coordinated solvents THF and $\mathrm{Et}_{2} \mathrm{O}$. The $\mathrm{Yb}(2)$ and $\mathrm{Yb}(3)$ ytterbium atoms in complex $\mathbf{I}$ are divalent, whereas $\mathrm{Yb}(1)$ has the formal charge +3 . This representation is well consistent with the theoretical atomic charges in $\mathbf{I}_{\text {isol }}$. The charges on the ytterbium atoms in $\mathbf{I}_{\text {inv }}$ coincide with the DFT data at the semiquantitative level. The proportional differ-

Table 1. Distances of the $\mathrm{Yb}-\mathrm{O}$ bonds and $\mathrm{Yb} \cdots \mathrm{F}$ contacts in complex I according to the routine XRD data, theoretical DFT calculations $\left(\mathbf{I}_{\text {isol }}\right)$, and experimental-theoretical (with molecular invariom) $\left(\mathbf{I}_{\text {inv }}\right)$ studies

\begin{tabular}{c|c|c|c||c|c|c|c}
\hline Bond & $\mathbf{I}, \AA$ & $\mathbf{I}_{\text {isol }}, \AA$ & $\mathbf{I}_{\text {inv }}, \AA$ & Bond & $\mathbf{I}, \AA$ & $\mathbf{I}_{\text {isol }}, \AA$ & $\mathbf{I}_{\text {inv }}, \AA$ \\
\hline $\mathrm{Yb}(1)-\mathrm{O}(1)$ & $2.075(3)$ & 2.0722 & $2.081(3)$ & $\mathrm{Yb}(2)-\mathrm{O}(8)$ & $2.402(2)$ & 2.4586 & $2.411(3)$ \\
$\mathrm{Yb}(1)-\mathrm{O}(2)$ & $2.075(3)$ & 2.0646 & $2.083(3)$ & $\mathrm{Yb}(3)-\mathrm{O}(4)$ & $2.392(3)$ & 2.3762 & $2.391(3)$ \\
$\mathrm{Yb}(1)-\mathrm{O}(3)$ & $2.239(2)$ & 2.2617 & $2.241(3)$ & $\mathrm{Yb}(3)-\mathrm{O}(5)$ & $2.355(3)$ & 2.3864 & $2.359(3)$ \\
$\mathrm{Yb}(1)-\mathrm{O}(4)$ & $2.248(2)$ & 2.2644 & $2.248(3)$ & $\mathrm{Yb}(3)-\mathrm{O}(6)$ & $2.391(2)$ & 2.3970 & $2.395(3)$ \\
$\mathrm{Yb}(1)-\mathrm{O}(6)$ & $2.371(2)$ & 2.4033 & $2.370(3)$ & $\mathrm{Yb}(3)-\mathrm{O}(7)$ & $2.513(2)$ & 2.5191 & $2.516(3)$ \\
$\mathrm{Yb}(1)-\mathrm{O}(7)$ & $2.359(2)$ & 2.3853 & $2.360(3)$ & $\mathrm{Yb}(3)-\mathrm{O}(9)$ & $2.392(3)$ & 2.4861 & $2.400(3)$ \\
$\mathrm{Yb}(2)-\mathrm{O}(3)$ & $2.394(3)$ & 2.3948 & $2.395(3)$ & $\mathrm{Yb}(2)-\mathrm{F}(31)$ & $2.568(2)$ & 2.5871 & $2.570(3)$ \\
$\mathrm{Yb}(2)-\mathrm{O}(5)$ & $2.366(3)$ & 2.3975 & $2.367(3)$ & $\mathrm{Yb}(2)-\mathrm{F}(38)$ & $2.644(2)$ & 2.6523 & $2.649(3)$ \\
$\mathrm{Yb}(2)-\mathrm{O}(6)$ & $2.513(2)$ & 2.5110 & $2.518(3)$ & $\mathrm{Yb}(3)-\mathrm{F}(36)$ & $2.652(2)$ & 2.6120 & $2.653(3)$ \\
$\mathrm{Yb}(2)-\mathrm{O}(7)$ & $2.415(2)$ & 2.4222 & $2.415(3)$ & $\mathrm{Yb}(3)-\mathrm{F}(41)$ & $2.522(3)$ & 2.5692 & $2.526(3)$ \\
\hline
\end{tabular}


Table 2. Atomic charges in complex I obtained on the basis of $\mathbf{I}_{\text {isol }}$ and $\mathbf{I}_{\text {inv }}$ of the ED distribution

\begin{tabular}{l|c|c}
\hline \multicolumn{1}{c|}{ Atom } & $\mathbf{I}_{\text {isol }}, \mathrm{e}$ & $\mathbf{I}_{\text {inv }}, \mathrm{e}$ \\
\hline $\mathrm{Yb}(1)$ & 2.24 & 1.02 \\
$\mathrm{Yb}(2)$ & 1.67 & 0.78 \\
$\mathrm{Yb}(3)$ & 1.66 & 0.79 \\
$q(\mathrm{~F})$ & $-0.65 \ldots-0.63$ & $-0.62 \ldots-0.52$ \\
$q(\mathrm{C})$ & $-0.02 \ldots+1.75$ & $-0.67 \ldots+1.66$ \\
$q(\mathrm{O})$ & $-1.26 \ldots-1.08$ & $-1.05 \ldots-0.84$ \\
$q(\mathrm{H})$ & $0.01-0.12$ & $0.23-0.32$ \\
\hline
\end{tabular}

ence between the charge on the formally trivalent $\mathrm{Yb}(1)$ atom and divalent $\mathrm{Yb}(2,3)$ atoms is retained. An analysis of the published data showed that the theoretically calculated values of charges on the metal atoms in the isolated molecules were more positive than the values obtained by the high-resolution XRD studies $[16,39]$. Thus, less positive charges on the ytterbium atoms in $\mathbf{I}_{\text {inv }}$ are quite expected.

The topology of the theoretical and experimentaltheoretical ED distributions in complex I was studied in the framework of R. Bader's theory "Atoms in Molecules" [40]. The main topological characteristics of $\mathbf{I}_{\text {isol }}$ and $\mathbf{I}_{\text {inv }}$ are compared in Table 3 . The main topological characteristics corresponding to the interactions of the ytterbium atoms in the coordination sphere are well consistent. All interactions $\mathrm{Yb}(\mathrm{II})-\mathrm{O}, \mathrm{Yb}(\mathrm{II}) \cdots \mathrm{F}$, and $\mathrm{Yb}(\mathrm{III})$ with the $\mu_{3}$-bridging hexafluoroisopropoxide ligands correspond to the closed shell type $\left(\nabla^{2} \rho(\mathbf{r})\right)>0$, $\left.h_{\mathrm{e}}(\mathbf{r})>0\right)$ in both $\mathbf{I}_{\text {isol }}$ and $\mathbf{I}_{\text {inv. }}$ In turn, all bonds of trivalent $\mathrm{Yb}(1)$ with the terminal and $\mu_{2}$-bridging hexafluoroisopropoxide ligands are classified as intermediate interactions $\left.\left(\nabla^{2} \rho(\mathbf{r})\right)>0, h_{\mathrm{e}}(\mathbf{r})<0\right)$ (Table 3). It is important that both models (theoretical and experimental-theoretical) make it possible to reveal four intramo-

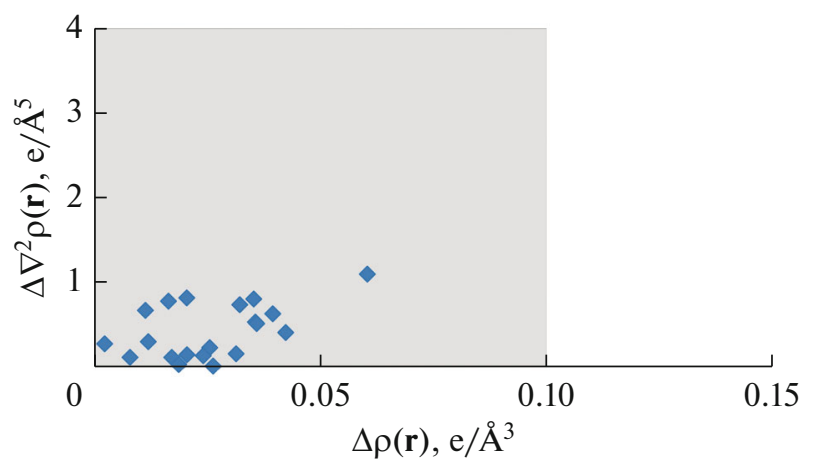

Fig. 3. Graphical representation of the deviation modules in the values of $\rho(\mathbf{r})$ and $\nabla^{2} \rho(\mathbf{r})$ at the CP $(3,-1)$ corresponding to the interactions of the ytterbium atoms in the coordination sphere between $\mathbf{I}_{\text {isol }}$ and $\mathbf{I}_{\text {inv. }}$. The gray region demonstrates the boundary of the transferability index. lecular $\mathrm{C}-\mathrm{F} \rightarrow \mathrm{Yb}$ interactions (Fig. 2). According to the Espinosa-Molins-Lecomte correlation [41], the energy of these interactions lies in ranges of 6.26-7.90 and 5.71$8.44 \mathrm{kcal} / \mathrm{mol}$ for $\mathbf{I}_{\text {isol }}$ and $\mathbf{I}_{\text {inv }}$, respectively. The presented values are only insignificantly lower than the corresponding values for the $\mathrm{Yb}(2)-\mathrm{O}(8)_{\mathrm{THF}}$ and $\mathrm{Yb}(3)-\mathrm{O}(9)_{\mathrm{EtOEt}}$ coordination bonds and interactions with the $\mu_{3}$-bridging hexafluoroisopropoxide ligands. The energy of $\mathrm{Yb}-\mathrm{O}\left(\right.$ iso- $\left.\mathrm{Pr}^{\mathrm{F}}\right)$ increases systematically from the $\mu_{3}$-bridging to terminal ligands in both $\mathbf{I}_{\text {isol }}$ and $\mathbf{I}_{\text {inv. }}$. This ED distribution in the coordination sphere of the lanthanide atoms in compound $\mathbf{I}$ also agrees well with the related europium complex $\left\{\mathrm{Eu}_{2}^{\mathrm{II}}\left(\mu_{2}-\mathrm{OCH}\left(\mathrm{CF}_{3}\right)_{2}\right)_{3}\left(\mu_{3^{-}}\right.\right.$ $\left.\left.\mathrm{OCH}\left(\mathrm{CF}_{3}\right)_{2}\right)_{2} \mathrm{Eu}^{\mathrm{III}}\left(\mathrm{OCH}\left(\mathrm{CF}_{3}\right)_{2}\right)_{2}(\mathrm{DME})_{2}\right\}$ [25].

The difference in $\rho(\mathbf{r})$ and $\nabla^{2} \rho(\mathbf{r})$ at the CP $(3,-1)$ corresponding to the $\mathrm{Yb}-\mathrm{O}$ and $\mathrm{Yb} \cdots \mathrm{F}$ interactions between models $\mathbf{I}_{\text {isol }}$ and $\mathbf{I}_{\text {inv }}$ does not exceed 0.009 and 0.046 a.u., respectively. Thus, the main topological characteristics for the interactions of the ytterbium atoms in the coordination sphere lie within the transferability index range for these values $\left(\rho(\mathbf{r})=0.1\right.$ e $\AA^{-3}$ (0.015 a.u.), $\nabla^{2} \rho(\mathbf{r})=4$ e $\AA^{-5}$ (0.17 a.u.)) [42] (Fig. 3).

The both methods (theoretical and experimentaltheoretical) expectedly allow numerous intramolecular nonvalent interactions $\mathrm{F} \cdots \mathrm{F}, \mathrm{F} \cdots \mathrm{H}$, and $\mathrm{F} \cdots \mathrm{O}$ to be found in the structure of complex I (Fig. 4). The following interactions were revealed totally by the study of the topology of the theoretical ED: 24 F $\cdots \mathrm{F}$, $24 \mathrm{~F} \cdots \mathrm{H}$, and $14 \mathrm{~F} \cdots \mathrm{O}$. It should be mentioned that the study of the topology of the experimental-theoretical ED makes it possible to reveal much less interactions involving fluorine atoms: $11 \mathrm{~F} \cdots \mathrm{F}, 13 \mathrm{~F} \cdots \mathrm{H}$, and $6 \mathrm{~F} \cdots \mathrm{O}$. The absolute values of the energy of these interactions and the total energies of all interactions involving the fluorine atoms in $\mathbf{I}_{\text {inv }}$ are lower than those in the $\mathbf{I}_{\text {isol }}$ model (Table 4). The distances corresponding to the $\mathrm{F} \cdots \mathrm{F}, \mathrm{F} \cdots \mathrm{H}$, and $\mathrm{F} \cdots \mathrm{O}$ interactions in complex I vary in rather wide ranges regardless of the method of obtaining the ED distribution. However, the range of determination of the interactions involving fluorine atoms is somewhat broader in $\mathbf{I}_{\text {isol }}$, and the maximum distances at which the interacting atoms are remote are longer (Table 4). The energy scatter for the corresponding interactions is also significant $(0.65-$ $4.11,0.23-2.25$, and $0.48-2.23 \mathrm{kcal} / \mathrm{mol}$ in $\mathbf{I}_{\text {isol }}$ and $0.53-1.67,0.33-1.54$, and $0.86-1.66 \mathrm{kcal} / \mathrm{mol}$ in $\left.\mathbf{I}_{\text {inv }}\right)$.

This difference in the number and energy of intramolecular nonvalent interactions involving the fluorine atoms in complex $\mathbf{I}$ is determined by geometry optimization in the theoretical study of the ED distribution in the molecule. An analysis of the geometry of the $\mathrm{F}^{\cdots} \mathrm{X}$ interactions $(\mathrm{X}=\mathrm{F}, \mathrm{H}, \mathrm{O})$ showed that the $I_{\text {inv }}$ model much more precisely reproduced the geometric characteristics determined in the routine XRD experiment than the $\mathbf{I}_{\text {isol }}$ model. The average deviations in the $\mathrm{F} \cdots \mathrm{F}, \mathrm{F} \cdots \mathrm{H}$, and $\mathrm{F} \cdots \mathrm{O}$ distances are 0.112 , 
Table 3. Selected topological characteristics of the $\mathrm{Yb}-\mathrm{O}$ bonds and $\mathrm{Yb} \cdots \mathrm{F}$ contacts in $\mathbf{I}_{\text {isol }}$ and $\mathbf{I}_{\text {inv }}$

\begin{tabular}{c|c|c|c|c|c|c|c|c}
\hline \multirow{2}{*}{ Bond } & \multicolumn{2}{|c|}{$\rho(\mathbf{r})$, a.u. } & \multicolumn{2}{|c|}{$\nabla^{2} \rho(\mathbf{r})$, a.u. } & \multicolumn{2}{c|}{$h_{\mathrm{e}}(\mathbf{r})$, a.u. } & \multicolumn{2}{|c}{$\mid E_{\text {EML }} *^{*}, \mathrm{kcal} / \mathrm{mol}$} \\
\cline { 2 - 8 } & $\mathbf{I}_{\text {isol }}$ & $\mathbf{I}_{\text {inv }}$ & $\mathbf{I}_{\text {isol }}$ & $\mathbf{I}_{\text {inv }}$ & $\mathbf{I}_{\text {isol }}$ & $\mathbf{I}_{\text {inv }}$ & $\mathbf{I}_{\text {isol }}$ & $\mathbf{I}_{\text {inv }}$ \\
\hline $\mathrm{Yb}(1)-\mathrm{O}(1)$ & 0.088 & 0.088 & 0.498 & 0.477 & -0.008 & -0.011 & 43.69 & 44.13 \\
$\mathrm{Yb}(1)-\mathrm{O}(2)$ & 0.089 & 0.087 & 0.501 & 0.472 & -0.009 & -0.010 & 44.70 & 43.30 \\
$\mathrm{Yb}(1)-\mathrm{O}(3)$ & 0.060 & 0.063 & 0.284 & 0.318 & -0.001 & -0.002 & 23.14 & 26.52 \\
$\mathrm{Yb}(1)-\mathrm{O}(4)$ & 0.060 & 0.063 & 0.281 & 0.314 & -0.001 & -0.002 & 22.87 & 25.97 \\
$\mathrm{Yb}(1)-\mathrm{O}(6)$ & 0.043 & 0.049 & 0.193 & 0.227 & 0.001 & 0.000 & 14.58 & 17.57 \\
$\mathrm{Yb}(1)-\mathrm{O}(7)$ & 0.045 & 0.050 & 0.203 & 0.234 & 0.001 & 0.000 & 15.38 & 18.22 \\
$\mathrm{Yb}(2)-\mathrm{O}(3)$ & 0.042 & 0.045 & 0.204 & 0.209 & 0.002 & 0.001 & 15.02 & 15.68 \\
$\mathrm{Yb}(2)-\mathrm{O}(5)$ & 0.042 & 0.047 & 0.203 & 0.225 & 0.002 & 0.001 & 14.90 & 17.07 \\
$\mathrm{Yb}(2)-\mathrm{O}(6)$ & 0.033 & 0.036 & 0.150 & 0.152 & 0.002 & 0.001 & 10.69 & 10.99 \\
$\mathrm{Yb}(2)-\mathrm{O}(7)$ & 0.040 & 0.044 & 0.191 & 0.201 & 0.002 & 0.001 & 13.95 & 15.19 \\
$\mathrm{Yb}(2)-\mathrm{O}(8)$ & 0.036 & 0.042 & 0.174 & 0.201 & 0.002 & 0.002 & 12.13 & 14.26 \\
$\mathrm{Yb}(3)-\mathrm{O}(4)$ & 0.044 & 0.045 & 0.215 & 0.210 & 0.002 & 0.001 & 15.84 & 15.75 \\
$\mathrm{Yb}(3)-\mathrm{O}(5)$ & 0.044 & 0.049 & 0.210 & 0.232 & 0.001 & 0.001 & 15.52 & 17.82 \\
$\mathrm{Yb}(3)-\mathrm{O}(6)$ & 0.043 & 0.046 & 0.206 & 0.212 & 0.001 & 0.001 & 15.22 & 16.21 \\
$\mathrm{Yb}(3)-\mathrm{O}(7)$ & 0.032 & 0.036 & 0.146 & 0.152 & 0.002 & 0.001 & 10.41 & 11.06 \\
$\mathrm{Yb}(3)-\mathrm{O}(9)$ & 0.034 & 0.043 & 0.162 & 0.207 & 0.002 & 0.002 & 11.23 & 14.83 \\
$\mathrm{Yb}(2) \cdots \mathrm{F}(31)$ & 0.022 & 0.026 & 0.112 & 0.119 & 0.002 & 0.003 & 7.50 & 7.31 \\
$\mathrm{Yb}(2) \cdots \mathrm{F}(38)$ & 0.019 & 0.023 & 0.095 & 0.094 & 0.002 & 0.003 & 6.26 & 5.71 \\
$\mathrm{Yb}(3) \cdots \mathrm{F}(36)$ & 0.021 & 0.022 & 0.106 & 0.093 & 0.002 & 0.003 & 7.07 & 5.64 \\
$\mathrm{Yb}(3) \cdots \mathrm{F}(41)$ & 0.023 & 0.029 & 0.118 & 0.135 & 0.002 & 0.003 & 7.90 & 8.44 \\
\hline $\mathrm{Th}-\mathrm{e})$
\end{tabular}

* The energy of the interactions was calculated by the Espinosa-Molins-Lecomte equation [41].

Table 4. Intramolecular interactions involving fluorine atoms in $\mathbf{I}_{\text {isol }}$ and $\mathbf{I}_{\text {inv }}$

\begin{tabular}{l|c|c|c|c|c|c|c|c}
\hline \multirow{2}{*}{ Contact } & \multicolumn{2}{|c|}{$\begin{array}{c}\text { Number } \\
\text { of contacts }\end{array}$} & \multicolumn{2}{c|}{$\begin{array}{c}\text { Range of changing } \\
\text { distance, } \AA\end{array}$} & \multicolumn{2}{c|}{$\begin{array}{c}\text { Range of changing energy } \\
\text { of contacts, kcal/mol }\end{array}$} & \multicolumn{3}{c}{$\begin{array}{c}\text { Total energy of contacts, } \\
\mathrm{kcal} / \mathrm{mol}\end{array}$} \\
\cline { 2 - 9 } & $\mathbf{I}_{\text {isol }}$ & $\mathbf{I}_{\text {inv }}$ & $\mathbf{I}_{\text {isol }}$ & $\mathbf{I}_{\text {inv }}$ & $\mathbf{I}_{\text {isol }}$ & $\mathbf{I}_{\text {inv }}$ & $\mathbf{I}_{\text {isol }}$ & $\mathbf{I}_{\text {inv }}$ \\
\hline $\mathrm{F} \cdots \mathrm{F}$ & 24 & 11 & $2.651-3.183$ & $2.768-3.164$ & $0.65-4.11$ & $0.53-1.67$ & 55.22 & 10.93 \\
$\mathrm{~F} \cdots \mathrm{H}$ & 24 & 13 & $2.341-3.146$ & $2.400-2.791$ & $0.23-2.25$ & $0.33-1.54$ & 26.14 & 11.86 \\
$\mathrm{~F} \cdots \mathrm{O}$ & 14 & 6 & $2.925-3.467$ & $2.901-3.167$ & $0.48-2.23$ & $0.86-1.66$ & 16.93 & 7.26 \\
\hline
\end{tabular}

0.184 , and $0.062 \AA$ in $\mathbf{I}_{\text {isol }}$ and $0.005,0.047$, and $0.009 \AA$ in $\mathbf{I}_{\text {inv }}$. The optimization of the molecular structure in the quantum-chemical calculation leads to the most energetically favorable conformation and ignores an intermolecular interaction in the crystal. Interestingly, during geometry optimization the highest changes are characteristic of the $\mathrm{F}^{\delta-} \ldots \mathrm{H}^{\delta+}$ interactions. The distances between these atoms decrease considerably due to the optimization. Therefore, it should be expected that the $\mathbf{I}_{\text {isol }}$ model somewhat overestimates the energy of these interactions. The overall contribution of all interactions $\mathrm{F}^{\delta-\ldots} \mathrm{F}^{\delta-}$ plays an important role in the stabilization of the molecular structure of complex I regardless of the approach to the study of the ED distribution. This conclusion is well consistent with the previously performed quantum-chemical study of the related europium complex [25].

In spite of such a significant difference in the energies of interactions, the main topological characteristics for the interactions involving the fluorine atoms, which can be localized in terms of both approaches to the study of the ED distribution in complex I, are in rather good agreement. The difference in $\rho(\mathbf{r})$ and $\nabla^{2} \rho(\mathbf{r})$ does not exceed 0.005 and 0.022 a.u., respectively. Thus, the main topological characteristics for the nonvalent interactions, which can be localized in the framework of both theoretical and experimentaltheoretical approaches, lie within the transferability 
(a)

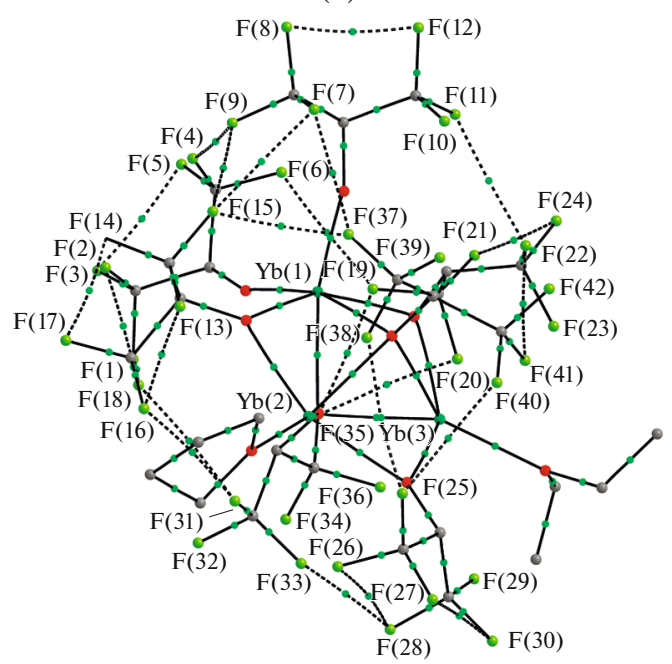

(c)

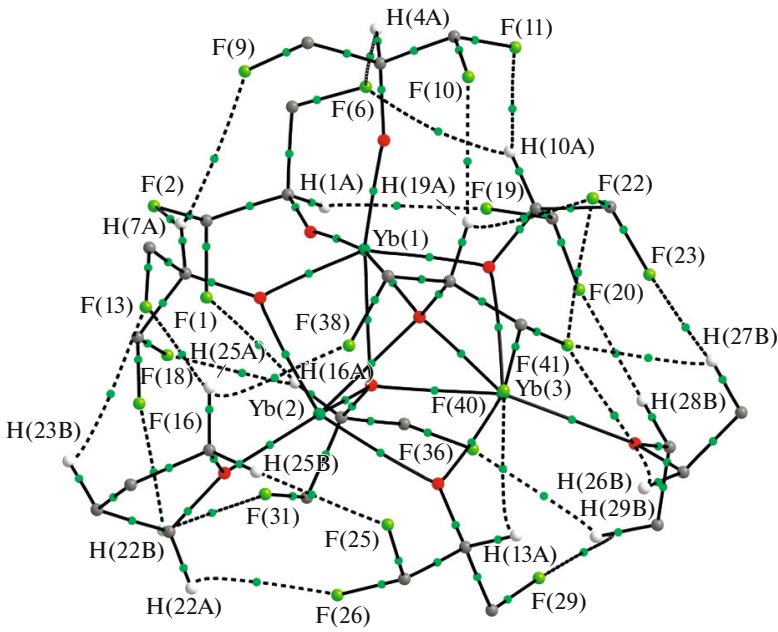

(e)

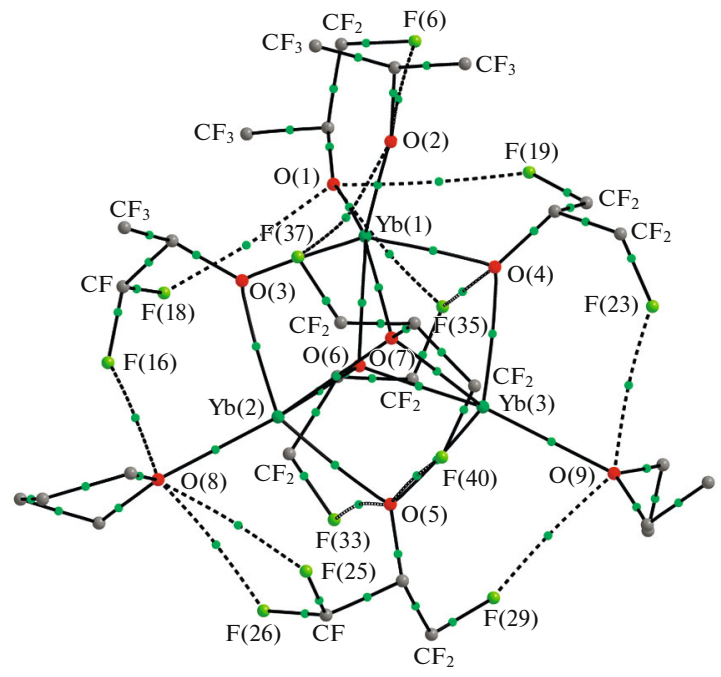

(b)

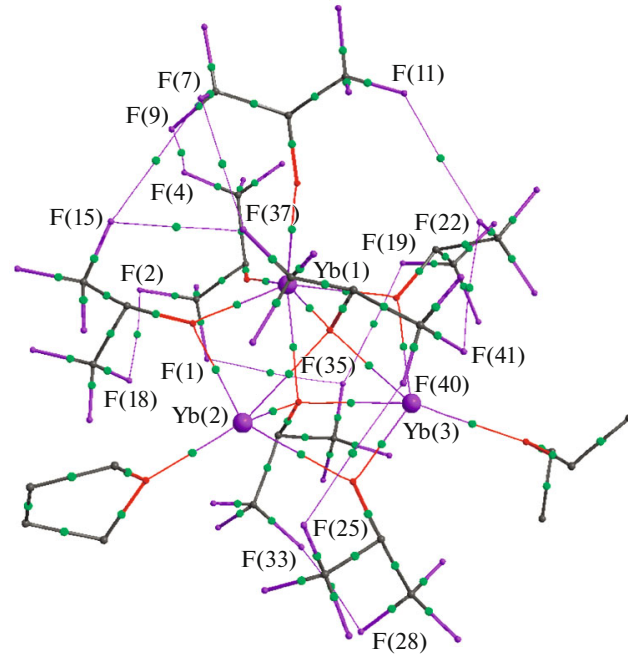

(d)

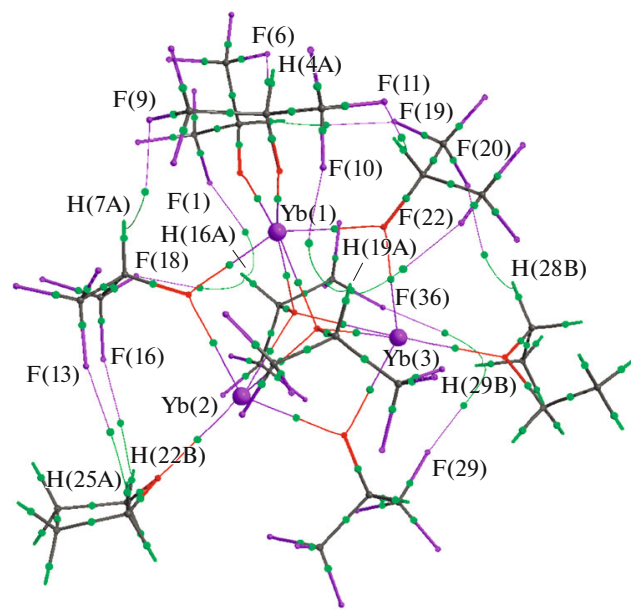

(f)

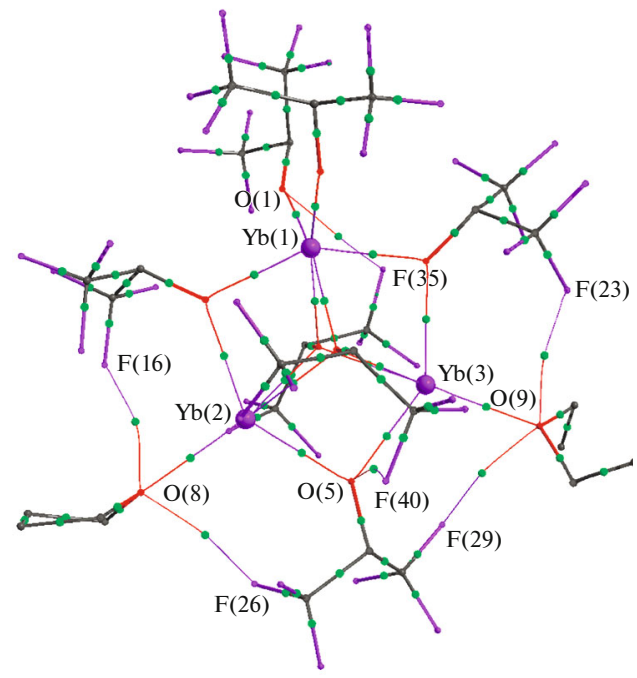

Fig. 4. (a, c, e) Theoretical ( $\left.\mathbf{I}_{\text {isol }}\right)$ and (b, d, f) experimental-theoretical ( $\left.\mathbf{I}_{\text {inv }}\right)$ molecular graphs for complex $\mathbf{I}$. Only selected CP $(3,-1)$ corresponding to the $(a, b) F \cdots F,(c, d) F \cdots H$, and $(e, f) F \cdots O$ interactions are presented separately for clarity. Hydrogen atoms are omitted. 


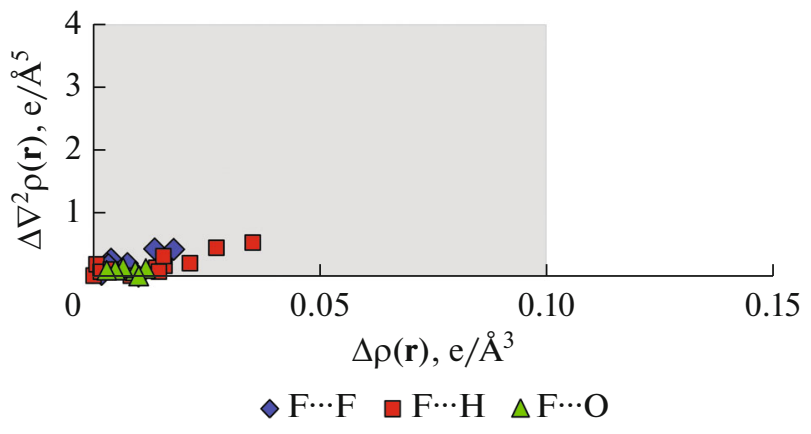

Fig. 5. Graphical representation of the deviation modules in the values of $\rho(\mathbf{r})$ and $\nabla^{2} \rho(\mathbf{r})$ at the CP $(3,-1)$ corresponding to the intramolecular interactions $F \cdots X(X=F$, $\mathrm{H}, \mathrm{O})$ between $\mathbf{I}_{\text {isol }}$ and $\mathbf{I}_{\text {inv. }}$. The gray region demonstrates the boundary of the transferability index.

index range of these values [42] (Fig. 5). The least average deviation in the values of $\rho(\mathbf{r})$ and $\nabla^{2} \rho(\mathbf{r})$ is observed for the F $\cdots \mathrm{O}$ interactions, while the largest is observed for the $\mathrm{F} \cdots \mathrm{H}$ interactions in strict accordance with the difference in bond lengths. The absolute values of the topological characteristics corresponding to the nonvalent interactions of the fluorine atoms are well consistent with the published data on the F $\cdots F$ interactions [43].

The studies of the experimental [44] and theoretical [25] DED distributions in the region of the halogen contacts $\mathrm{F}^{\delta-\cdots} \mathrm{F}^{\delta-}$ showed that fluorine $\cdots$ fluorine interactions are possible due to the donation of the ED from the region of its concentration on one of the atoms to the region of ED depletion on the second atom. The DED map was constructed for the $\mathbf{I}_{\text {inv }}$ model in the framework of the applicability of the experimental-theoretical approach to the study of the interactions involving the fluorine atoms in the structure of complex I. As can be seen from Fig. 6a, in the area where the $\mathrm{F}(28) \cdots \mathrm{F}(33)$ interaction occurs, the region of ED accumulation on $\mathrm{F}(28)$ rigidly corre- sponds to the region of ED depletion on the F(33) atom. Note that the molecule of complex I contains the shortened pairs of atoms $F \cdots$ F for which $C P$ $(3,-1)$ were not localized either in the case of the theoretical approach, or when using the experimentaltheoretical approach to obtaining the ED distribution. For example, the $F(33) \cdots F(36)$ distance in $\mathbf{I}_{\mathrm{inv}}$ is 2.774(4) $\AA$. This value lies in the range of interactions characteristic of F $\cdots \mathrm{F}$ (Table 4), but the CP and bonding route for this pair of atoms were not localized (Fig. 4b). In order to determine the principal distinction of such noninteracting pairs of atoms, we constructed the DED distribution in $\mathbf{I}_{\text {inv }}$ in the $\mathrm{C}(17)-$ $F(33) \cdots F(36)$ plane (Fig. 6b). Unlike the $F(28) \cdots F(33)$ interaction, the $F(33)$ and $F(36)$ atoms are arranged relative to each other in such a way that the region of ED accumulation on one of the atoms corresponds to the ED accumulation region on the second atom. This is the reason for the absence of interactions between the atoms $F(33) \cdots F(36)$. The distribution of the theoretical DED in the region of nonvalent interactions of fluorine in the molecule of $\mathbf{I}_{\text {isol }}$ excellently reproduces the data of the $\mathbf{I}_{\text {inv }}$ model.

In addition to the nonvalent interactions involving the fluorine atoms $\mathrm{F} \cdots \mathrm{F}, \mathrm{F} \cdots \mathrm{O}, \mathrm{F} \cdots \mathrm{H}$, and $\mathrm{C}-\mathrm{F} \rightarrow \mathrm{Yb}$ in the structure of the $\mathbf{I}_{\text {isol }}$ model, the following intramolecular contacts are localized: three $\mathrm{O} \cdots \mathrm{H}$ and two $\mathrm{O} \cdots \mathrm{O}$. The energy of the $\mathrm{O} \cdots \mathrm{H}$ interactions is 0.93 , 1.33 , and $1.65 \mathrm{kcal} / \mathrm{mol}$, and that of $\mathrm{O} \cdots \mathrm{O}$ is 3.36 and $4.24 \mathrm{kcal} / \mathrm{mol}$. An analysis of the topology of the ED in $\mathbf{I}_{\text {inv }}$ did not allow localizing the $\mathrm{O} \cdots \mathrm{H}$ interaction in the molecule. However, one of two $\mathrm{O} \cdots \mathrm{O}$ interactions found in $\mathbf{I}_{\text {isol }}$ is reproduced in $\mathbf{I}_{\text {inv. }}$. The CP $(3,-1)$ is localized between the oxygen atoms of the $\mu_{3}$-bridging hexafluoroisopropoxide ligands. The energy of this interaction calculated by the Espinosa-MolinsLecomte equation [41] is 4.24 and $4.96 \mathrm{kcal} / \mathrm{mol}$ in $\mathbf{I}_{\text {isol }}$ and $\mathbf{I}_{\text {inv }}$, respectively. (a)

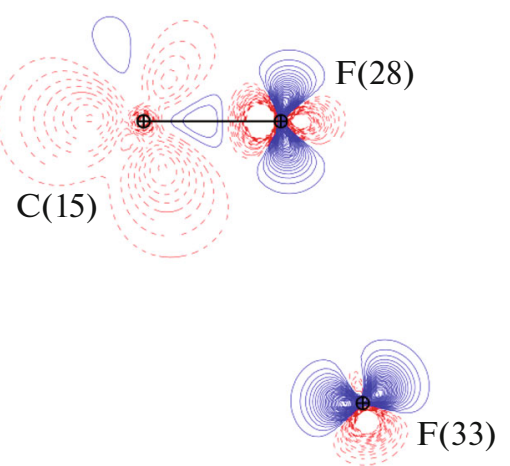

(b)

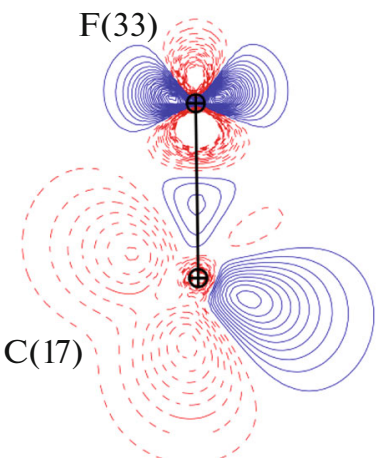

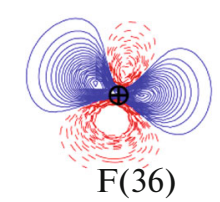

Fig. 6. Distribution of the DED (0.05 a.u.) in complex $\mathbf{I}_{\text {inv }}$ in the (a) $C(15)-F(28) \cdots F(33)$ and (b) $C(17)-F(33) \cdots F(36)$ planes. The regions of ED concentration are marked by solid lines, and the regions of ED depletion are indicated by dashed lines. 
To conclude, the topology of the ED distribution in complex I obtained by the theoretical (quantumchemical DFT calculation) and experimental-theoretical (molecular invariom) methods was studied. The main topological characteristics corresponding to the interactions of the ytterbium atoms in the coordination sphere range within the transferability index between $\mathbf{I}_{\text {isol }}$ and $\mathbf{I}_{\text {inv }}$. This assertion is valid, in particular, for the intramolecular interactions $\mathrm{C}-\mathrm{F} \rightarrow \mathrm{Yb}$ in complex I. Geometry optimization leads to a stronger change in the geometry compared to the use of the molecular invariom model. As a result, the number of intramolecular interactions involving the fluorine atoms and their energy in $\mathbf{I}_{\text {isol }}$ are much higher than those in $\mathbf{I}_{\text {inv }}$. However, the main topological characteristics $\left(\rho(\mathbf{r})\right.$ and $\left.\nabla^{2} \rho(\mathbf{r})\right)$ corresponding to the $F \cdots X$ interactions $(X=F, H, O)$, which can be localized in terms of both studied approaches, lie within the transferability indices of these values. The study of the DED distribution in $\mathbf{I}_{\text {inv }}$ showed that the $\mathrm{F}^{\delta-\ldots} \mathrm{F}^{\delta-}$ interactions can occur due to the correspondence of the region of ED concentration on one of the atoms to the region of ED depletion on another atom regardless of the method of obtaining the ED distribution in the molecule.

\section{FUNDING}

This work was supported by the Russian Science Foundation, project no. 17-73-20302.

\section{CONFLICT OF INTEREST}

The authors declare that they have no conflicts of interest.

\section{OPEN ACCESS}

This article is licensed under a Creative Commons Attribution 4.0 International License, which permits use, sharing, adaptation, distribution and reproduction in any medium or format, as long as you give appropriate credit to the original author(s) and the source, provide a link to the Creative Commons license, and indicate if changes were made. The images or other third party material in this article are included in the article's Creative Commons license, unless indicated otherwise in a credit line to the material. If material is not included in the article's Creative Commons license and your intended use is not permitted by statutory regulation or exceeds the permitted use, you will need to obtain permission directly from the copyright holder. To view a copy of this license, visit http://creativecommons.org/licenses/by/4.0/.

\section{REFERENCES}

1. Gatti, C. and Matta, C.F., Modern Charge-Density Analysis, Heidelberg: Springer, 2012.

2. Dittrich, B. and Matta, C.F., IUCrJ, 2014, vol. 1, p. 457.
3. Abramov, Yu.A., Acta Crystallogr., Sect. A: Found. Crysrallogr., 1997, vol. 53, p. 264.

4. Tsirel'son, V.G., Sorosovskii Obrazovatel'nyi Zh., 2000, vol. 6, no. 6, p. 94.

5. Santos, G.M., Catellani, I.B., Bini, R.D., et al., Ferroelectrics, 2016, vol. 500, no. 1, p. 26.

6. Zhigulin G.Yu., Zabrodina G.S., Katkova M.A., et al., Russ. Chem. Bull., 2019, no. 4, p. 743.

7. Sangwan, R., Saini, M., Verma, R., et al., J. Mol. Struct., 2020, vol. 1208. ID 127786.

8. Dittrich, B., Koritsnszky, T., and Luger, P., Angew. Chem., Int. Ed. Engl., 2004, vol. 43, p. 2718.

9. Dittrich, B., Hubschle, C.B., Luger, P., and Spackman, M.A., Acta Crystallogr., Sect. D: Biol. Crystallogr., 2006, vol. 62, p. 1325.

10. Wandtke, C.M., Weil, M., Simpson, J., et al., Acta Crystallogr., Sect. B: Struct. Sci., Cryst. Eng. Mater., 2017, vol. 73, p. 794.

11. Dittrich, B., Wandtke, C.M., Meents, A., et al., ChemPhysChem, 2015, vol. 16, p. 412.

12. Malischewski, M., Seppelt, K., Sutter, J., et al., Angew. Chem., Int. Ed. Engl., 2017, vol. 56, p. 13372.

13. Fukin, G.K., Baranov, E.V., Cherkasov, A.V., et al., Russ. J. Coord. Chem., 2019, vol. 45, no. 10, p. 680. https://doi.org/10.1134/S1070328419090045

14. Nelyubina, Y.V., Korlyukov, A.A., Lyssenko, K.A., et al., Inorg. Chem., 2017, vol. 56, p. 4688.

15. Fukin, G.K., Baranov, E.V., Cherkasov, A.V., et al., Russ. Chem. Bull., 2019, no. 9, p. 1650.

16. Fukin, G.K., Cherkasov, A.V., Baranov, E.V., et al., Chemistry Select., 2019, vol. 4, p. 10976.

17. Kovalenko, A.A., Nelyubina, Y.V., Korlyukov, A.A., et al., Z. Kristallogr. Cryst. Mater, 2018, vol. 233, no. 5, p. 317.

18. Problema belka. T. 3: Strukturnaya organizatsiya belka (Protein Problem, Vol. 3: Protein Structural Organization), Popov, E.M., Ed., Moscow: Nauka, 1997.

19. Evans, W.J., Forrestal, K.J., Ansari, M.A., et al., J. Am. Chem. Soc., 1998, vol. 120, p. 2180.

20. Liu, B., Roisnel, T., Maron, L., et al., Chem.-Eur. J., 2013, vol. 19, p. 3986.

21. Maleev, A.A., Fagin, A.A., Ilichev, V.A., et al., J. Organomet. Chem., 2013, vol. 747, p. 126.

22. Melman, J.H., Rohde, C., Emge, T.J., et al., Inorg. Chem., 2002, vol. 41, p. 28.

23. Kuzyaev, D.M., Rumyantsev, R.V., Fukin, G.K., et al., Russ. Chem. Bull., 2014, no. 4, p. 848.

24. Kuzyaev, D.M., Balashova, T.V., Burin, M.E., et al., Dalton Trans., 2016, vol. 45, p. 3464.

25. Rumyantsev, R.V. and Fukin, G.K., Russ. J. Coord. Chem., 2019, vol. 45, no. 11, p. 767. https://doi.org/10.1134/S1070328419110058

26. Frisch, M.J., Trucks, G.W., Schlegel, H.B., et al., Gaussian09. Revision D.01, Wallingford: Gaussian, Inc., 2009.

27. Schuchardt, K.L., Didier, B.T., Elsethagen, T., et al., J. Chem. Inf. Model, 2007, vol. 47, no. 3, p. 1045.

28. Ditchfield, R., Hehre, W.J., and Pople, J.A., J. Chem. Phys., 1971, vol. 54, p. 724. 
29. Hehre, W.J., Ditchfield, R., and Pople, J.A., J. Chem. Phys., 1972, vol. 56, p. 2257.

30. Hariharan, P.C. and Pople, J.A., Theor. Chim. Acta, 1973, vol. 28 , p. 213.

31. Clark, T., Chandrasekhar, J., Spitznagel, G.W., et al., J. Comput. Chem., 1983, vol. 4, p. 294.

32. Dolg, M., Stoll, H., and Preuss, H., J. Chem. Phys., 1989, vol. 90, p. 1730.

33. AIMAll (version 17.11.14), Todd A. Keith, Overland Park: TK Gristmill Software, 2017 (aim.tkgristmill.com).

34. Jorge, F.E., Martins, L.S.C., and Franco, M.L., Chem. Phys. Lett., 2016, vol. 643, p. 84.

35. Jayatilaka, D. and Grimwood, D.J., Comput. Sci. ICC, 2003, vol. 2660, p. 142.

36. Jelsch, C., Guillot, B., Lagoutte, A., et al., J. Appl. Crystallogr., 2005, vol. 38, p. 38.
37. Stash, A. and Tsirelson, V., J. Appl. Crystallogr., 2002, vol. 35 , p. 371 .

38. Lu, T. and Chen, F., J. Comput. Chem., 2012, vol. 33, p. 580.

39. Fukin, G.K., Baranov, E.V., and Jelsch, C., J. Phys. Chem. A, 2011, vol. 115, p. 8271.

40. Bader, R.F., Atoms in Molecules: A Quantum Theory, Oxford: Oxford Univ. Press, 1990.

41. Espinosa, E., Molins, E., and Lecomte, C., Chem. Phys. Lett., 1998, vol. 285, p. 170.

42. Checinska, L., Mebs, S., Hubschle, C.B., et al., Org. Biomol. Chem., 2006, vol. 4, p. 3242.

43. Karnoukhova, V.A., Fedyanin, I.V., and Lyssenko, K.A., Struct. Chem., 2016, vol. 27, p. 17.

44. Hathwar, V.R. and Guru Row, T.N., Cryst. Growth Des., 2011, vol. 11, p. 1338.

Translated by E. Yablonskaya 